\title{
DEVELOPMENT OF AN OS CALCANEAL SPUR IN A BOY BETWEEN THE AGES OF 10 AND 14 YEARS
}

\author{
BY \\ B. REEVES \\ Hospital for Sick Children, Great Ormond Street, London
}

Calcaneal spurs are seen frequently in adults with rheumatoid disease, ankylosing spondylitis, and Reiter's syndrome; the differences between the mature spurs have been well described by Mason, Murray, Oates, and Young (1959). The process of development of these spurs does not, however, appear to have been recorded. It was therefore thought that this series of $x$ rays taken over a 4-year period starting at the age of 10 years would be of interest.

\section{Case Report}

A 9-year-old boy presented with an 18 months' history of a lump on the dorsum of the right foot and a limp. This limp was associated with the first metatarso-medial cuneiform joint and operation showed it to be caused by hyperplastic synovium, which had the histological appearance of rheumatoid disease when examined after biopsy. $X$ ray of the foot at this time revealed slight generalized porosis and diminution of the first metatarso-medial cuneiform joint. The erythrocyte sedimentation rate was $8 \mathrm{~mm}$./1 $\mathrm{hr}$ (Westergren).

One year later he began to feel pain in the right heel and was found on examination to have a spasmodic valgus of the right foot, calf wasting, and a tender area just anterior to the insertion of the plantar fascia into the os calcis. An $x$ ray (Fig. 1) revealed early new bone formation in the form of a small smooth mass of periosteal new bone on the plantar surface of the os calcis anterior to the epiphyseal line.

Intermittent pain continued in the right foot, being occasionally severe enough to prevent his playing games. $X$ rays of the foot taken at the ages of 12 and 13 (Figs 2 and 3) showed that the new bone formation had become diffuse and that when epiphyseal fusion had occurred at age 13 the new bone had taken the appearance of a classical spur. At the age of 14 there was a severe exacerbation of rheumatoid disease necessitating treatment with steroids. However, despite steroid therapy and plaster immobilization, he continued to have increasing and severe pain in the region of this spur though the other joints symptomatically regressed (Fig. 4). The spur was therefore excised and complete relief of pain followed.

\section{Discussion}

The four $x$ rays taken over a 4-year period show the gradual development of a calcaneal spur in a boy with rheumatoid disease. Initially this is just a little periosteal new bone formation on the plantar surface of the os calcis anterior to the epiphysis; this increases in size and a concave nodule is formed at the insertion of the plantar fascia; finally, there is marked osteoporosis with florid spur formation and a large amount of periosteal new bone formation on the plantar surface of the os calcis.

In this patient steroids failed to check progressive formation of the calcaneal spur and it was later necessary to excise the spur together with the insertion of the plantar fascia to relieve his pain.

\section{Summary}

The development of a calcaneal spur over a 4-year period in a boy with rheumatoid disease is described.

I should like to thank Mr. G. C. Lloyd-Roberts and Dr. B. E. Schlesinger for their permission to publish this case.

\section{REFERENCE}

Mason, R. M., Murray, R. S., Oates, J. K., and Young, A. C. (1959). J. Bone Jt Surg., 41-B, 317. 
Développement d'un éperon calcanéen chez un garçon aux âges de 10 à 14 ans

\section{RÉSUMÉ}

On décrit le développement d'un éperon calcanéen pendant une période de 4 ans chez un garçon atteint de maladie rhumatoïde.

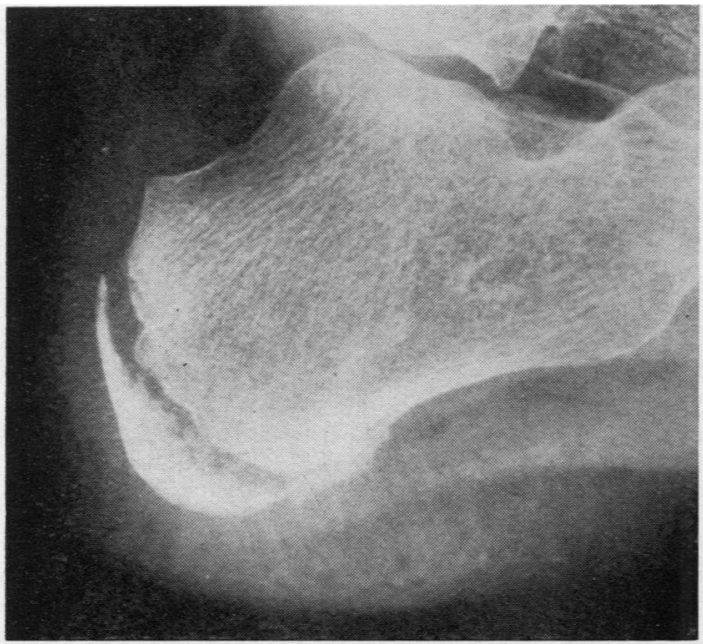

Fig. 1.-Lateral view of os calcis at age 10, showing a small smooth mass of periosteal new bone formation on the plantar surface just anterior to the epiphyseal line.

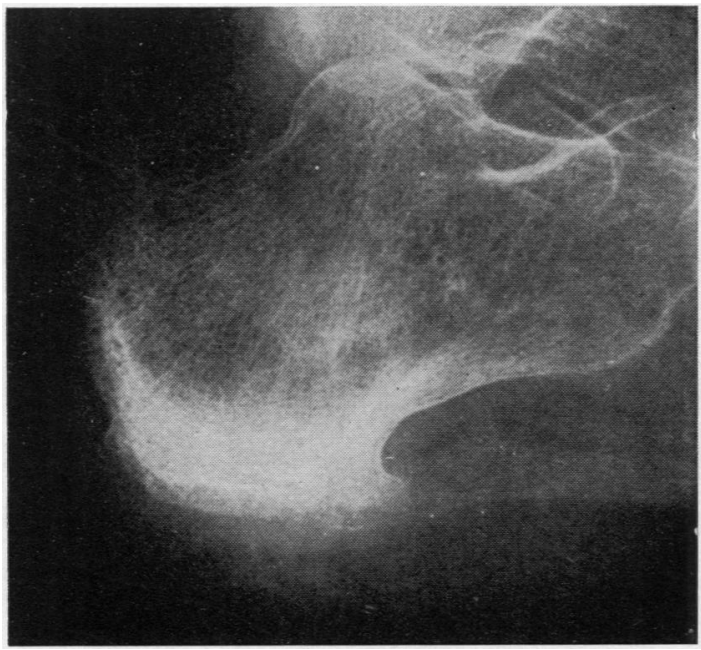

Fig. 3.-At age 13 epiphyseal fusion has occurred and a classical os calcis spur is seen.
Desarrollo de una espuela del calcáneo en un chico entre las edades de 10 a 14 años

\section{Sumario}

Se describe el desarrollo de una espuela del calcáneo durante un período de 4 años en un joven con enfermedad reumatoide.

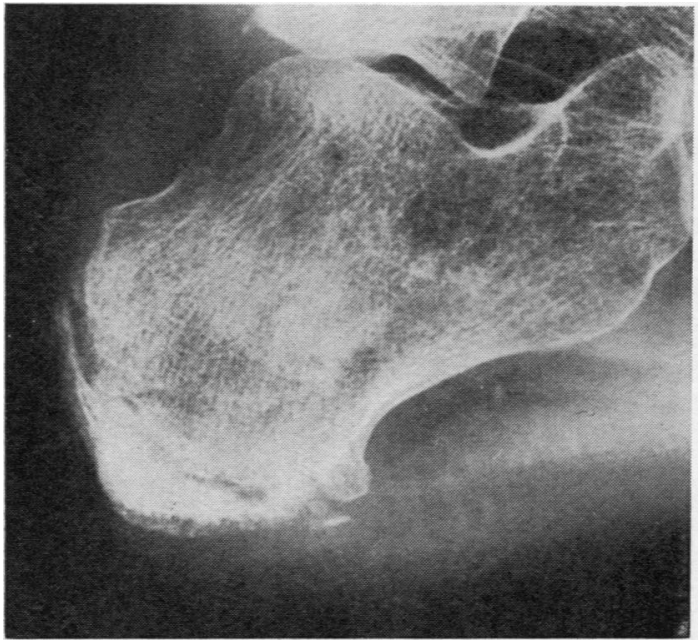

Fig. 2.-At age 12 a small rounded mass of cancellous bone anterior to the epiphyseal line is seen.

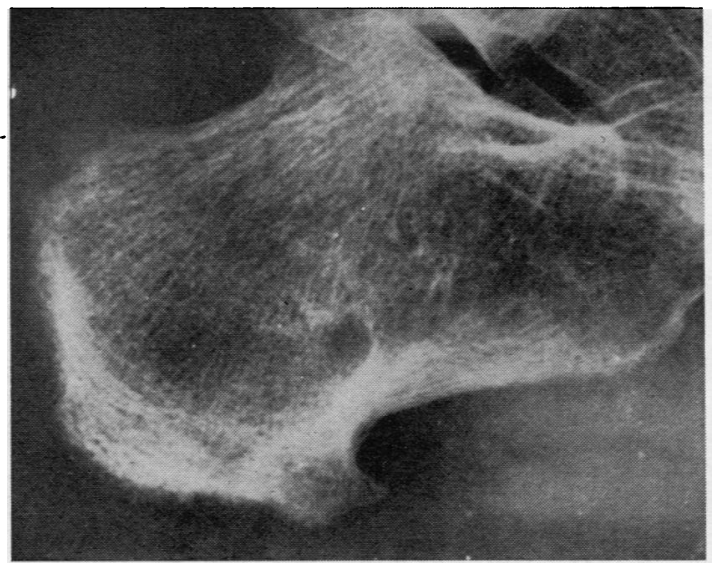

Fig. 4. - The os calcis spur just before excision at age 14 . 